\title{
A novel adsorbent for heavy metal remediation in aqueous environments
}

\author{
${ }^{1 *}$ C. M. Zvinowanda; ${ }^{1}$ J. O. Okonkwo; ${ }^{2}$ P. N. Shabalala; ${ }^{3}$ N. M. Agyei \\ ${ }^{1}$ Department of Environmental Water and Earth Sciences, Tshwane University of Technology, South Africa \\ ${ }^{2}$ AER (Environmental Business Services Section), SGS Group, Johannesburg, South Africa \\ ${ }^{3}$ Chemistry Department, University of Limpopo, MEDUNSA, South Africa \\ Received 10 February 2009; ～revised 14 April 2009; accepted 17 May 2009; $\quad$ available online 1 June 2009
}

\begin{abstract}
The objective of this study was to investigate the possibility of using maize tassel as an alternative adsorbent for the removal of chromium (VI) and cadmium (II) ions from aqueous solutions. The effect of $\mathrm{pH}$, solution temperature, contact time, initial metal ion concentration and adsorbent dose on the adsorption of chromium (VI) and cadmium (II) by tassel was investigated using batch methods. Adsorption for both chromium (VI) and cadmium (II) was found to be highly $\mathrm{pH}$ dependent compared to the other parameters investigated. Obtained results gave an adsorption capacity of $79.1 \%$ for chromium (VI) at $\mathrm{pH} 2$, exposure time of $1 \mathrm{~h}$ at $25{ }^{\circ} \mathrm{C}$. Maximum capacity of cadmium of $88 \%$ was obtained in the $\mathrm{pH}$ range of 5-6 at $25{ }^{\circ} \mathrm{C}$ after exposure time of $1 \mathrm{~h}$. The adsorption capacities of tassel for both chromium (VI) and cadmium (II) were found to be comparable to those of other commercial adsorbents currently in use for the removal of heavy metals from aqueous wastes. These results have demonstrated the immense potential of maize tassel as an alternative adsorbent for toxic metal ions remediation in polluted water and wastewater.
\end{abstract}

Keywords: Adsorption capacity; Batch studies; Energy dispersive x-ray; Fourier transform infrared; Maize tassel

\section{INTRODUCTION}

A heavy metal is a metal of relatively high specific gravity greater than 5 or high atomic weight, one that is poisonous like lead, mercury, chromium and cadmium (Bailey et al., 1999; Lakatos et al., 2002). Chromium and cadmium have been selected in this study because of their inherent toxicity to most organisms (Merroun et al.,1998; Wan Ngah and Hanafiah, 2008). These metals are major pollutants in South Africa's water resources due to their use in many industries, such as metal plating, mining operations and tanneries. Some metals associated with these activities are lead, mercury, cadmium and chromium (Abdel-Ghani et al., 2007; Abia and Igwe, 2005; Bailey et al., 1999; Dang et al., 2009; Zvinowanda et al., 2009b).

$\mathrm{Cr}$ (III) is essential trace element needed for glucose metabolism in humans, plants and animals. It is relatively innocuous and immobile when compared to $\mathrm{Cr}$ (VI) compounds. $\mathrm{Cr}(\mathrm{VI})$ moves rapidly through soils and aquatic environments and is a strong oxidizing agent capable of being absorbed through the skin. The maximum concentration limit for chromium (VI) for

ब*Corresponding Author Email: zvinowandacm@tut.ac.za Tel.: +2712 382 6281; Fax: +2712 3826354 discharge into inland surface waters is $0.1 \mathrm{mg} / \mathrm{L}$ and in potable water is $0.05 \mathrm{mg} / \mathrm{L}$ (Dubey and Krishna, 2007). The major sources of Cd (II) and Cr (VI) compounds are ferrochrome processing and metal plating industries (Álvarez-Ayuso and García-Sánchez, 2007; Amuda et al., 2007; Dakkiy et al., 2002; Gupta et al., 1999).

Because of the high positive charge of $\mathrm{Cr}(\mathrm{VI})$, it is hydrolysed to form oxo-anions, $\mathrm{CrO}_{4}^{2-}, \mathrm{HCrO}_{4}^{-}$and $\mathrm{Cr}_{2} \mathrm{O}_{7}^{2-}$ depending on the $\mathrm{pH}$ of the media (Mohan and Pittman, 2006). At low $\mathrm{pH}$ and high chromium (VI) concentration, it exists predominantly as dichromate $\left(\mathrm{Cr}_{2} \mathrm{O}_{7}^{2-}\right)$; while at $\mathrm{pH}$ greater than $6.5, \mathrm{Cr}(\mathrm{VI})$ exists as a chromate $\left(\mathrm{CrO}_{4}^{2-}\right)$. At pH less than 2, the $\mathrm{HCrO}_{4}^{-}$is the dominant species. Acute exposure to $\mathrm{Cr}(\mathrm{VI})$ causes nausea, diarrhoea, liver and kidney damage, dermatitis, internal haemorrhage and respiratory problems (Singh et al., 2007). Inhalation may cause acute toxicity, irritation and ulceration of the nasal septum and respiratory sensitisation (asthma). Injection may affect kidney and liver functions. Skin contact may result in systematic poisoning damage or even severe burns, and interference with the healing of cuts or scrapes (Jusoh et al., 2007; Naiya et al., 2009; Wang et al., 2009). If not 
treated properly this may lead to ulceration and severe chronic allergic contact dermatitis. Eye exposure may cause permanent damage (Cohen, 2006).

Cadmium in nature exists mainly in the +2 oxidation state, which gives stable compounds. The major sources of Cd (II) in most water bodies include mining through acid mine drainage and battery manufacturing industries. Cadmium is a non-essential element and is one of the most hazardous trace elements, which is classified as a "priority metal" from the standpoint of potential hazard to human health and plant life (Singh et al., 2007; Vandecasteele et al., 2007; Zhu et al., 2007). The most crucial problem of heavy metal pollution is that the metals and their speciation products are non bio-degradable hence tend to accumulate until above lethal concentration levels (LC). The level of chromium and cadmium in discharged wastewater should be reduced, or recycled if possible. Several technologies have been developed to remove heavy metals and their speciation products from wastewater or contaminated water in order to make water usable. However, the literature is still insufficient to cover this problem and more work and investigations are needed to deal with other locally available and cheap adsorbents to eliminate $\mathrm{Cr}$ (VI) and Cd (II) from industrial wastewater with different compositions and characteristics (Babel and Kumiawan, 2004; Kurniawan et al., 2006; O’Connell et al., 2008; Malakootian et al., 2009).

The minimisation of the environmental impact of transition and heavy metals in aquatic systems and leachates requires the application of different chemical processes such as precipitation, ion- exchange, adsorption, electrochemical precipitation, membrane filtration, reverse osmosis, solvent extraction, electrodialysis, sedimentation, flotation, phyto-remediation, electro-coagulation, electro-kinetic extraction, cementation, evaporation, dilution, stripping, flocculation and chelation (Doyurum and Celik, 2006; Lakatos et al., 2002; Karbassi et al., 1994). Chemical precipitation has been the most used method from the list (Mohan and Pittman, 2006).

Currently, activated carbon is the major material used in the extraction of gold from its aqueous solutions. However, as already referred to, the use of CAC in heavy metal uptake from aqueous waste is constrained by the high cost of this material which can not be financially compensated, as in gold processing. In recent years, number of agricultural materials such as palm kernel husk, modified cellulosic material, corn cobs, residual lignin, wool, apple residues, olive mill products, polymerized orange skin, banana husk, pine back, sawdust, coals, etc. have been reported for their removal of toxic metals from aqueous solutions (Bailey et al., 1999; Doyurum and Celik, 2006; Lakatos et al., 2002; Srivastava et al., 1986). However, most of these agricultural materials investigated so far have limitations in terms of efficiency and their adsorption capacities for heavy metals. The limitations of some of the aforementioned technologies which include high cost, unavailability, generation of large volumes of secondary waste and poor removal efficiency has necessitated the continued search for new adsorbent materials. Tassel is an agricultural material which can be investigated for its possible in adsorption technology. The application of agricultural materials in wastewater treatment has been reported (Doyurum and Celik, 2006; Kumar, 2006; Lakatos et al., 2002; Mohan and Pittman, 2006; Namasiyayam and Yamuna, 1995). From the more than hundred agricultural materials reported, no studies have been carried out on tassel except reports from this group (Zvinowanda et al., 2008a, b; 2009a, b). Tassel is found in large quantities from maize producing countries such as South Africa, Mexico, Argentina and USA. In the present study, an attempt has been made to investigate the possibility of using maize tassel as sustainable adsorbent for toxic metal remediation in aqueous environments under different experimental conditions.

The study was carried out at Arcadia Campus, in the Department of Environmental Water and Earth Sciences, Faculty of Science, TUT, Pretoria in 2007 and most of the experimental work was performed in the Environmental Chemistry Research Labratory.

\section{MATERIALS AND METHODS}

For both chromium and cadmium, stock solutions were prepared by dissolving $3.734 \mathrm{~g}$ of $\mathrm{K}_{2} \mathrm{CrO}_{4} \cdot 6 \mathrm{H}_{2} \mathrm{O}$ and $2.7442 \mathrm{~g}$ of Cd $\left(\mathrm{NO}_{3}\right)_{2} \cdot 4 \mathrm{H}_{2} \mathrm{O}$, respectively in $1000 \mathrm{~mL}$ volumetric flasks and made up to the mark with deionised water. All the required working solutions were prepared by diluting the stock solutions with deionised water.

The maize tassel used in the present study was prepared by crushing air dried tassels (collected from TUT farm) by hand to reduce into smaller particles. The smaller particles were then dried in the oven at $100{ }^{\circ} \mathrm{C}$ for $24 \mathrm{~h}$ to reduce the moisture content. The material was then milled into a mixture of finer particles with different particle diameters. The course powder was further fractionated into different particle sizes using 
analytical sieves. The most common particle fractions were A(50-150 $\mu \mathrm{m}), \mathrm{B}(150-300 \mu \mathrm{m})$ and C (300-500 $\mu \mathrm{m})$ diameters. In this study, fraction $\mathrm{A}(50-150 \mu \mathrm{m})$ was used throughout the experiments. Fourier transform infrared (FTIR) and energy dispersive x-ray (EDX) spectra of the adsorbent were recorded on Perkin- A Perkin-Elmer GX2000 FTIR spectrometer adapted with Perkin-Elmer auto image microscope system and JSM 5800LV, Vantage 6, analytical systems with $130 \mathrm{eV}$ detector (JEOL, Tokyo, Japan), respectively. Samples for FTIR were prepared by diluting the adsorbent to $5 \%$ in $\mathrm{KBr}$ and cast in disks for analysis. Analysis of standards and simulated samples was done using an AA140 atomic absorption spectrometer, linked to a HP Compaq with an HP L1906 monitor and mine waste samples were analysed using ICP-OES.

\section{Batch studies}

Batch experiments for chromium (VI)

Batch experiments were carried out using a series of erlenmeyer flasks of $100.0 \mathrm{~mL}$ capacity. Batch experiments were conducted to investigate the effects of $\mathrm{pH}$, contact time, initial Cr (VI) and Cd (II) concentrations, adsorbent dose and temperature on adsorption of the material ions from its solutions. All the adsorption experiments were carried out at room temperature $\left(25 \pm 2^{\circ} \mathrm{C}\right)$ except where the effect of temperature was being investigated. The initial $\mathrm{pH}$ was adjusted with $1 \mathrm{M} \mathrm{HNO}_{3}$ or $1 \mathrm{M} \mathrm{NaOH}$ solutions.

\section{The effect of $p H$ on adsorption of metal ions}

The effect of $\mathrm{pH}$ on adsorption was investigated in the pH range $2.0-10$ at $25^{\circ} \mathrm{C}$. The initial $\mathrm{pH}$ of the $\mathrm{Cr}$ (VI) solution was adjusted from $\mathrm{pH} 3$ to the desired value by adding few drops of $1.0 \mathrm{M} \mathrm{HNO}_{3}$ to get a $\mathrm{pH} 2$ solution. Solutions of $\mathrm{pH} 4$-10 were prepared by adding few drops of $1.0 \mathrm{M} \mathrm{NaOH}$ solutions to the $\mathrm{pH} 3$ solution. The same procedure was repeated for Cd (II) (in pH range 3-6).

\section{The effect of metal ion concentration on adsorption}

For kinetic studies, $1.0 \mathrm{~g}$ of the adsorbent was shaken with $100.0 \mathrm{~mL}$ of $\mathrm{Cr}$ (VI) solution of varying concentrations (25,150, 300 and $400 \mathrm{mg} / \mathrm{L})$ in different $100.0 \mathrm{~mL}$ Erlenmeyer flasks. The contents were continuously agitated in a temperature controlled water bath with a shaker at $100 \pm \mathrm{rpm}$. At the end of the predetermined time intervals (60 min), the adsorbent was filtered and Cr (VI) concentration in the filtrate was determined using FAAS. The adsorbed amount was determined from the difference in the initial and residual concentrations of $\mathrm{Cr}$ (VI) in the liquid phase. The same procedure was repeated for Cd (II) samples.

\section{The effect of adsorbent dose on metal ion adsorption}

Adsorption dose experiments were also performed with $100 \mathrm{~mL}$ of $150 \mathrm{mg} / \mathrm{L} \mathrm{Cr}$ (VI) solution with the following adsorbent masses $0.2,0.4,0.6,0.8,1.0,1.2,1.4$, 1.6, 1.8 and $2.0 \mathrm{~g}$ at $25^{\circ} \mathrm{C}$. The $\mathrm{pH}$ of the solution was adjusted to optimum $\mathrm{pH} 2$. After the established contact time (1h) was reached, the suspension was filtered and filtrate analysed for unadsorbed metal ion concentrations. The adsorbed metal ions were obtained by the difference. The same procedure was repeated for Cd (II), but at optimum pH 6.

The effect of contact time on the removal of metal ions Experiments for the effect of time were also performed following the same procedure, as described earlier, but at a fixed $\mathrm{pH} 2$ for $\mathrm{Cr}$ (VI) fixed temperature $\left(25 \pm 2^{\circ} \mathrm{C}\right)$, fixed concentration $(150 \mathrm{mg} / \mathrm{L})$ and adsorbent dose (1.0 $\mathrm{g} / 100 \mathrm{~mL}$ ). Six sets of samples prepared in triplicate were placed in a water bath with a shaker set at 100rpm. After every $30 \mathrm{~min}$, three samples were removed and filtered immediately and the filtrate was analysed. Cd (II) was analysed using the same procedure at its optimum $\mathrm{pH} 6$.

\section{The effect of solution temperature on metal adsorption}

Lastly, experiments for the reaction temperature was also performed following the same procedure, with all other parameters fixed, but at different temperature ranges, $25,35,45,55,60,70,80$ and $100^{\circ} \mathrm{C}$. Each analysis was done in triplicate in order to get accurate results for both Cr (VI) and Cd (II).

\section{Data quality assurance}

Blanks were prepared for each experimental parameter: $\mathrm{pH}$, contact time, solution temperature, metal ion concentration and adsorbent dose. The prepared blanks were treated exactly the same way the samples were treated. For $\mathrm{pH}$, contact time, adsorbent dose and temperature blanks were subjected to their average values. During the analysis, the instrument FAAS, was programmed in such a way that a blank measurement was made before each sample measurement. The actual concentration of non adsorbed metal ions, $\mathrm{C}_{\mathrm{t}}$, was calculated using the equation:

$C_{t}=C_{m}-C_{b l k}$ 
Where, $\mathrm{C}_{\mathrm{t}}=$ true concentration of $\mathrm{Cr}(\mathrm{VI})$ or Cd(II) still present in solution after reaction; $\mathrm{C}_{\mathrm{m}}=$ measured $\mathrm{Cr}(\mathrm{VI})$ or $\mathrm{Cd}(\mathrm{II})$ present in solution; $\mathrm{C}_{\mathrm{blk}}=$ blank concentration.

\section{Statistical analysis}

All experiments were setup in triplicates and relative standard deviation (RSD) was calculated for each result. Any triplicate set with an RSD greater that $5 \%$ was rejected and such experiments were repeated to get a better reliability.

\section{RESULTS AND DISCUSSION}

\section{Calculations}

When maize tassel powder was tested for its ability to adsorb $\mathrm{Cr}$ (VI) and Cd (II) ions from aqueous solution, initial $\mathrm{pH}$ of 2 was used for the most experiments. The effects of the following experimental parameters on adsorption which included initial concentration, adsorbent dosage, $\mathrm{pH}$, temperature and the exposure time were studied. All the investigations were carried out as batch experiments for the two metal ions. The uptake or adsorption percent of Cr (VI) and Cd (II) was calculated from the following equation:

$$
\% \text { Adsorption (uptake \%) }=\left(\left(C_{o}-C_{f}\right) / C_{o}\right) \times 100
$$

Where $\mathrm{C}_{\mathrm{o}}=$ the initial concentrations $(\mathrm{mg} / \mathrm{L}) ; \mathrm{C}_{\mathrm{f}}=$ final concentrations (mg/L). The adsorption capacity of $\mathrm{Cr}$ (VI) or Cd(II) is the concentration of Cr(VI) or Cd(II) on the adsorbent mass and was calculated based on the mass balance principle,

Where:

$q_{m-}$ (adsorption capacity $=\left(C_{o}-C_{f}\right) \times V / m$

In which, $\mathrm{q}_{\mathrm{m}}=$ amount of Cr (VI) or Cd (II) per dry weight of tassel; $\mathrm{V}=$ the volume of reaction mixture (L); $\mathrm{m}=$ the mass of adsorbent used(g); $\mathrm{C}_{\mathrm{o}}=$ the initial concentrations (mg/L) and $\mathrm{C}_{\mathrm{f}}=$ final concentrations (mg/L)

\section{FTIR and EDX analysis of adsorbent}

The FT-IR spectrum (Fig. 1) of tassel was used to identify functional groups present on the maize tassel that could be responsible for uptake of heavy metal species. The spectrum of the adsorbent was measured within the range of $4000-600 / \mathrm{cm}$ wave number. The absorption peak around 3466/cm indicates the existence of O-H groups. The peaks observed at $2921 / \mathrm{cm}$ can be assigned to stretching vibration of the $\mathrm{C}-\mathrm{H}$ group. The absorption peaks at 1734, 1643 and $1036 / \mathrm{cm}$ are associated with the presence of $\mathrm{C}=\mathrm{O}, \mathrm{C}=\mathrm{C}$ and C-O, respectively (Cardenas and Miranda, 2004; Chauhan et al., 2006). The EDX spectrum obtained for tassel is shown in Fig. 2. The elemental distribution of tassel shows high percentage levels of $\mathrm{Al}, \mathrm{Mg}$ and $\mathrm{Si}$ elements with potential to form organometallic compounds which might be responsible for the tough elastic properties exhibited by the tassel powder.

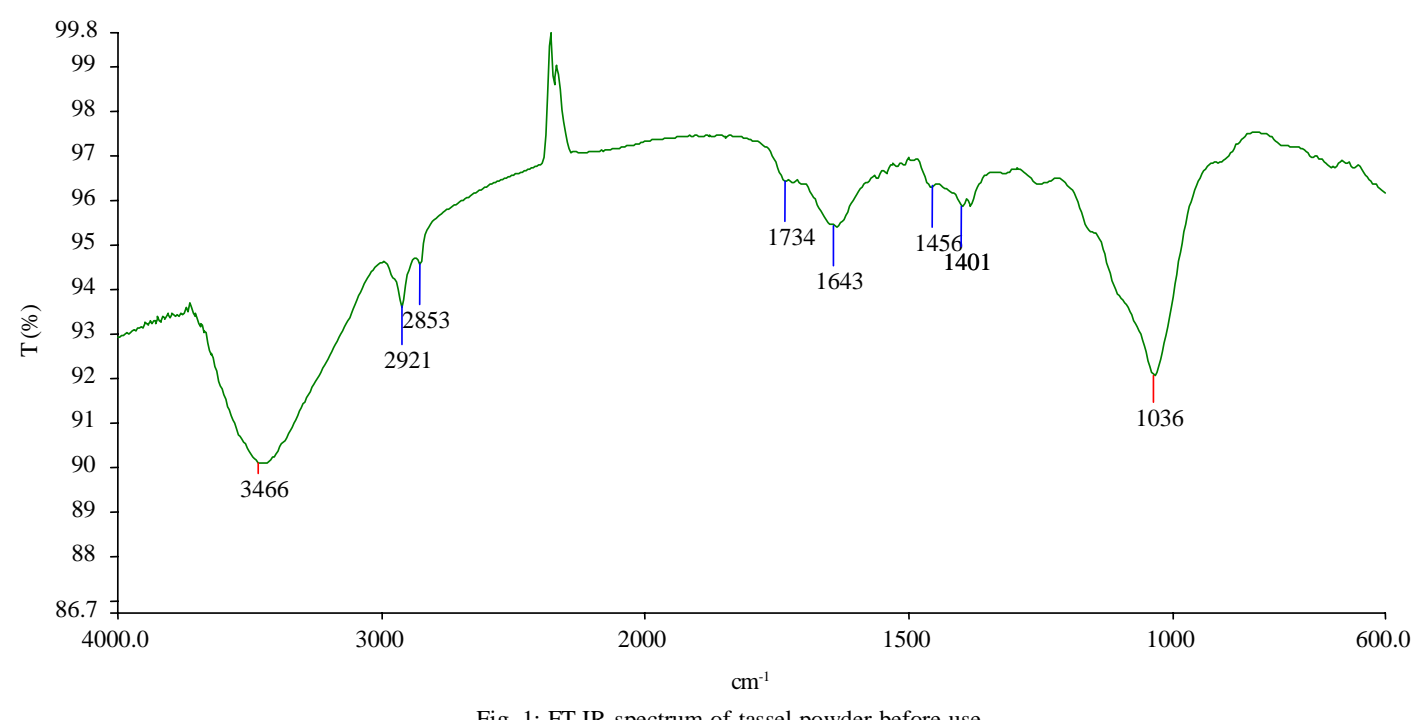




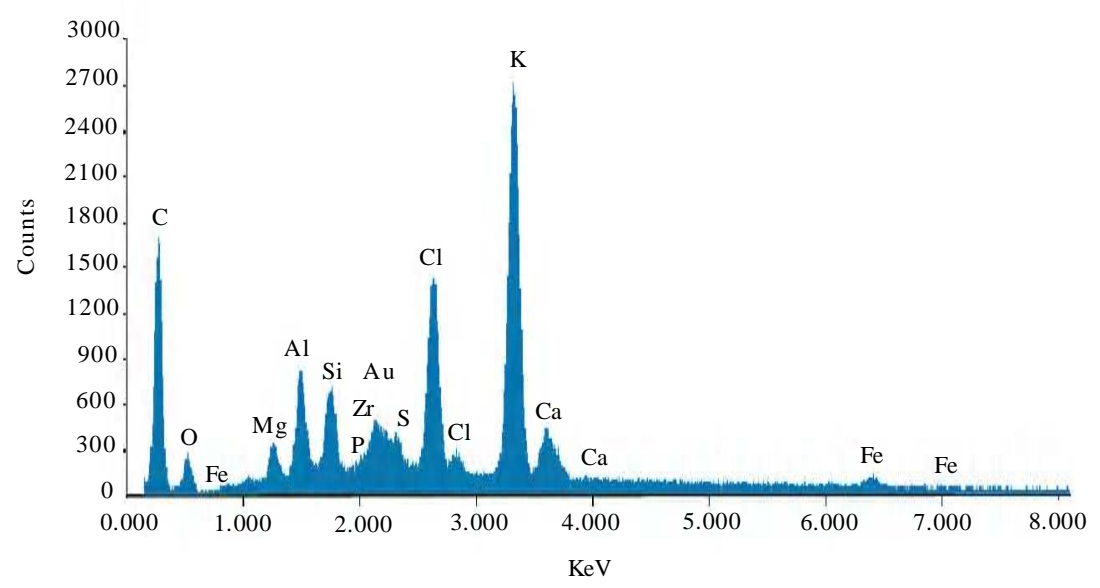

Fig. 2: EDX spectrum of tassel powder before use

Adsorption of $\mathrm{Cr}(\mathrm{VI})$

Effects of Cr (VI) concentration

The effects of varying $\mathrm{Cr}$ (VI) concentration on adsorption capacity while the other four parameters were kept constant is shown in Fig. 3. The adsorption of $\mathrm{Cr}$ (VI) ions by the adsorbent initially increased rapidly with increasing $\mathrm{Cr}(\mathrm{VI})$ concentration and slowed down when $\mathrm{Cr}$ (VI) concentration reached $300 \mathrm{mg} / \mathrm{L}$ (Fig. 3). The initial rapid increase in the uptake of $\mathrm{Cr}(\mathrm{VI})$ can be attributed to the interactions between the metal ions and the active sites of the adsorbent. At higher concentrations more $\mathrm{Cr}$ (VI) ions are left un-adsorbed in solution due to the saturation of binding sites. The graph levels off between 400 and $500 \mathrm{mg} / \mathrm{L}$ due to total saturation of the binding sites of the tassel. From similar studies conducted by Malkoc et al. (2006), the adsorption of $\mathrm{Cr}(\mathrm{VI})$ on pomace at $25^{\circ} \mathrm{C}$ gave $\mathrm{q}_{\mathrm{m}}$ values of $6.10,10.34,10.80$ and $2.12 \mathrm{mg} / \mathrm{L}$ for solutions of concentrations 50, 100, 150 and $200 \mathrm{mg} / \mathrm{L}$, respectively. These results are similar to the observations made in this studies where the adsorption capacity of tassel for $\mathrm{Cr}$ (VI) was in the range $1.8-10 \mathrm{mg} / \mathrm{g}$. The work by Dubey and Krishna (2007), found that the maximum adsorption capacity of most investigated biosorbents were in the range of $1.6 \mathrm{mg} / \mathrm{g}-13.4 \mathrm{mg} / \mathrm{g}$ for unmodified bisorbents.

\section{Effects of $p H$ on metal ion adsorption}

The effects of $\mathrm{pH}$ on the adsorption of $\mathrm{Cr}$ (VI) is presented in Fig. 4. The $\mathrm{pH}$ of the aqueous solution is an important operational parameter in the adsorption process. This is because it affects the solubility of the metal ions concentration of the counter ions on the functional groups of the adsorbent and the degree of ionization of adsorbate during reaction (Amuda et al., 2007). The $\mathrm{pH}$ was varied from 1 to 9 , while the other operational parameters (adsorbent dosage, agitation time, initial ion concentration and reaction temperature) were kept at the optimum. Temperature, agitation speed, adsorbent dose and contact time were kept at $25^{\circ} \mathrm{C}, 100$ rpm, $10.0 \mathrm{~g} / \mathrm{L}$ and $1 \mathrm{~h}$, respectively. Generally, the adsorption capacity of tassel on $\mathrm{Cr}$ (VI) decreased with increase in solution $\mathrm{pH}$. However, there was some slight increase in adsorption between $\mathrm{pH}$ 6-8.

From Fig. 4, it can be seen that there is a sharp decrease of adsorption from $\mathrm{pH} 2$ reaching the minimum at pH 5. There is a slight increase of adsorption thereafter to $\mathrm{pH}$ of about 8 , a slight decrease followed by a marginal increase and finally a fall. The sorption capacity of $\mathrm{Cr}$ (VI) at $\mathrm{pH} 2.0$ by tassel was $4.5 \mathrm{mg} / \mathrm{g}$, which reduced to $1.0 \mathrm{mg} / \mathrm{g}$ at $\mathrm{pH} 5.0$. Similar studies using waste pomace of olive oil factory (WPOOF) gave adsorption capacity of $8.5 \mathrm{mg} / \mathrm{g}$ and $2.7 \mathrm{mg} / \mathrm{g}$ at $\mathrm{pH}$ of 2.0 and 5.0 , respectively (Malkoc et al., 2006). The adsorption process is explained as follows: at low $\mathrm{pH}$, there is a large number of $\mathrm{H}^{+}$ions, which in turn neutralise the negatively charged adsorbent surface thereby reducing hindrance to the difusion of dichromate ions (Mohan and Pittman, 2006). Hence, the sorption increases with increase in the acidity of the solution. As the $\mathrm{pH}$ increases, the concentration of $\mathrm{OH}^{-}$ions increases and overall charge on the adsorbent surface becomes negative which 


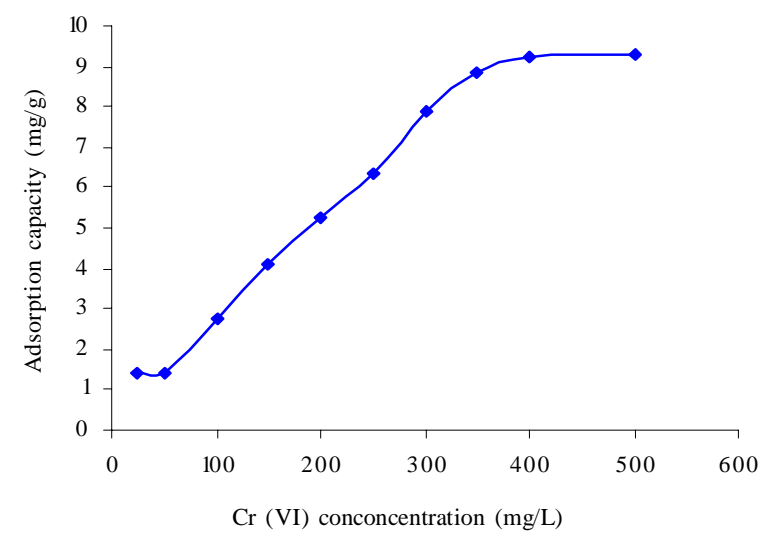

Fig. 3: Effect of initial concentration on adsorption capacity of tassel

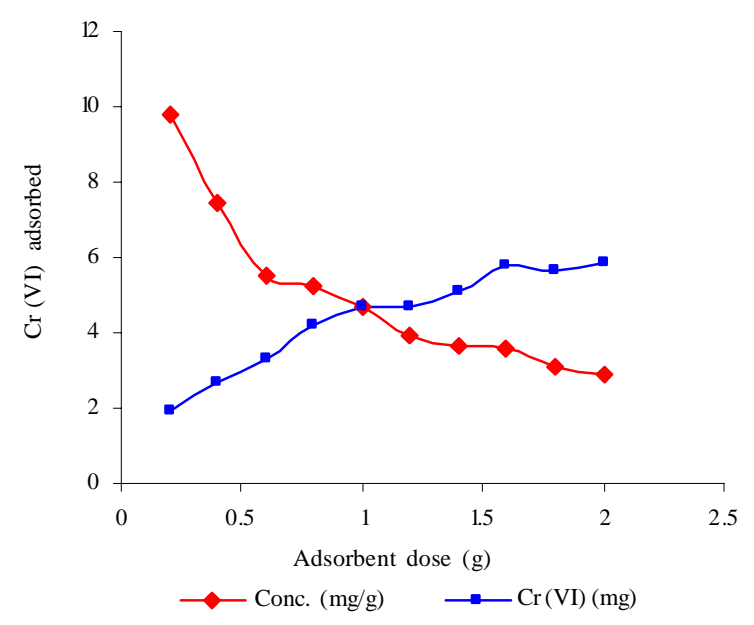

Fig. 5: Effect of adsorbent dose on Cr (VI) adsorption

causes hindrance in the sorption of negatively charges $\mathrm{Cr}(\mathrm{VI})$ ions like $\mathrm{Cr}_{2} \mathrm{O}_{7}^{2-}, \mathrm{CrO}_{4}^{2-}$ and $\mathrm{HCrO}_{4}$ - This results in decreased sorption of $\mathrm{Cr}$ (VI) at high $\mathrm{pH}$ (Mohan and Pittma, 2006). The other possible mechanism of adsorption of $\mathrm{Cr}(\mathrm{VI})$ is through the oxidation of the adsorbent surface to groups like carboxylic $(\mathrm{COOH})$, carbonyl $(\mathrm{C}=\mathrm{O})$ and hydroxyl $(\mathrm{OH})$ groups. $\mathrm{Cr}(\mathrm{VI})$ is then reduced to $\mathrm{Cr}$ (III) which is positively charged and will be attracted to negatively charged functional groups generated on the surface of adsorbent by oxidation.

\section{Effect of adsorbent concentration/ dosage}

The removal of chromium(VI) by tassel at different adsorbent doses( 0.2-2.0 g in $100 \mathrm{~mL}$ i.e 2-20 g/L) for the chromium concentration $150 \mathrm{mg} / \mathrm{L}$ was studied. The other parameters were fixed as follows: contact time: $1 \mathrm{~h}$, agitation speed: 100rpm and an optimum $\mathrm{pH}$ : 2 . The results in Fig. 5 show that the the adsorption capacity of

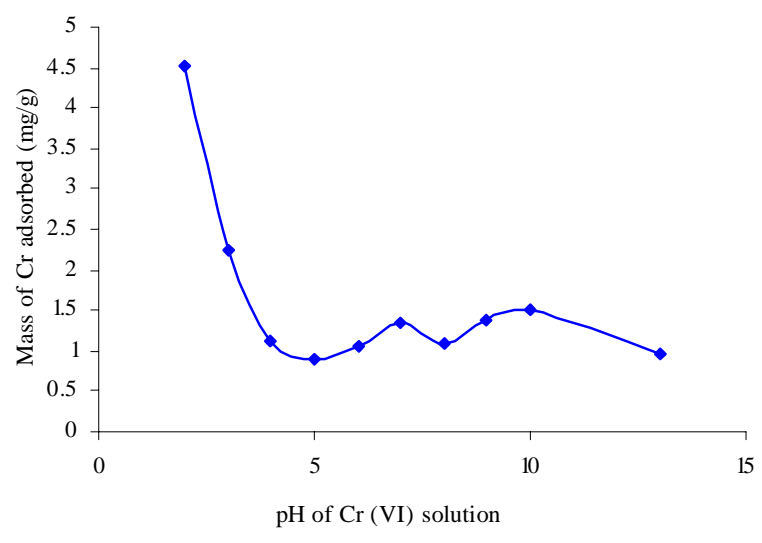

Fig. 4: Effect of $\mathrm{pH}$ on the adsorption of $\mathrm{Cr}$ (VI) on the adsorbent

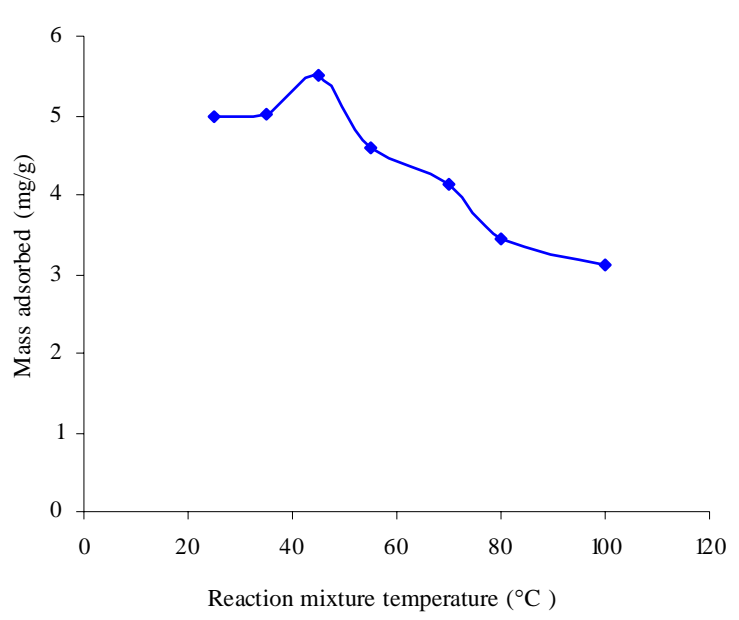

Fig. 6: Effect of temperature on $\mathrm{Cr}$ (VI) adsorption

Cr (VI) decreased rapidly with increase in the dose of tassel. However, conversion of adsorption capacity to metal ion uptake gave an increase in \% adsorbed. These results are in agreement with studies by Malkoc et al., (2006). They observed an increase in Cr (VI) uptake from 51.7 to $98.6 \%$ as the dose concentration was increased from $5-15 \mathrm{mg} / \mathrm{L}$. However, the sorption efficiency showed a reverse trend to the removal percentage adsorptions. With increase in adsorbent dose from 2.0 to $20 \mathrm{mg} / \mathrm{L}$, i.e. from 0.2 to $2.0 \mathrm{~g}$ of adsorbent in $100 \mathrm{~mL}$ of solution, the adsorption of Cr (VI) ion per unit weight of adsorption decreased from 9.8 (66.7\%) to 3.0 $\mathrm{mg} / \mathrm{g}(33.3 \%)$.

\section{Effect of temperature on Cr (VI) adsorption}

The adsorption of $\mathrm{Cr}$ (VI) from aqueous solutions at different temperatures was investigated. Samples were subjected to temperatures which ranged from 25 to 
$100^{\circ} \mathrm{C}$. As can be seen in Fig. 6, the adsorption capacity increased to a maximum which was reached at $45^{\circ} \mathrm{C}$ and thereafter it decreased gradually. The maximum adsorption efficiency of $5.5 \mathrm{mg} / \mathrm{g}$ (36.6 \%) occurred at $45{ }^{\circ} \mathrm{C}$. From the effect of temperature studies using WPOOF conducted by Malkoc et al. (2006) on the adsorption of $\mathrm{Cr}(\mathrm{VI})$, it was observed that the adsorption capacity of $\mathrm{Cr}$ (VI) incresed with temperature. This was observed in the temperature range $45^{\circ} \mathrm{C}-60^{\circ} \mathrm{C}$ for the concentration range $50-200 \mathrm{mg} / \mathrm{L}$. When the solution temperature was increased, this increased the oxidising power of the $\mathrm{Cr}$ (VI) ions. The ions were then reduced to $\mathrm{Cr}$ (III) and were bound strongly on the organic material. However, overheating might result in desorption kinetics dominating.

\section{The effect of contact time on Cr (VI) adsorption}

The effect of contact time on the adsorption of $\mathrm{Cr}(\mathrm{VI})$ from its solution is shown in Fig. 7. There is a general increase in the \% adsorption of $\mathrm{Cr}(\mathrm{VI})$ with time. However, the adsorption slowed down after about 120 min. This could possibly be the time required for the equilibrium to be established. Generally, an equalibrium is established at the surface of the adsorbent after sometime or it can be instantaneous. The equilibrium utake of $\mathrm{Cr}$ (VI) was about $68 \%$. The equilibrium was established after $120 \mathrm{~min}$. They also investigated the effect of temperature on the time taken to establish equilibrium.

\section{Effects of Cd (II) concentration}

The impact of concentartion on the adsorption capacity of tassel powder for Cd (II) in shown in Fig. 8. As can be seen from Fig. 8, there is a general increase in adsorption of Cd (II) up to a concentration of $300 \mathrm{mg} / \mathrm{L}$, thereafter, the adsorption levels off, remaining almost constant. To investigate the effects of the $\mathrm{Cd}^{2+}$ concentration on the uptake of this metal, the process was carried out with initial $\mathrm{Cd}^{2+}$ concentrations between 25 and $500 \mathrm{mg} / \mathrm{L}$. The agitation speed, $\mathrm{pH}$, contact time and adsorbent dose were fixed at values of $100 \pm 5 \mathrm{rpm}$, $\mathrm{pH} 3,1 \mathrm{~h}$ and $0.1 \mathrm{~g}$. The material showed good adsorption of $\mathrm{Cd}^{2+}$ ions as the percentage removal of $3-6 \%$ per 0.1 $\mathrm{g}$ tassel equivalent to the calculated ranged from 30 to $68 \%$ per $1 \mathrm{~g}$ tassel. The levelling of the curve after 300 $\mathrm{mg} / \mathrm{L}$ can be attributed to the saturation of adsorption active sites. From the studies done by Doyurum and Celik (2006), adsorption Cd (II) was done using olive cake. There was a general increase in Cd (II) adsorption by olive cake and saturation was established at about $250 \mathrm{mg} / \mathrm{L}$. These experiments were carried out at $\mathrm{pH} 4.5$ at a temperature of $30^{\circ} \mathrm{C}$. An adsorption uptake of 51.4 $\%$ for Cd (II) using olive cake was achieved.

\section{Effects of pH on Cd (II) adsorption}

The impact of $\mathrm{pH}$ on the uptake of Cd (II) ions by tassel is shown in Fig. 9. The removal percentage of $\mathrm{Cd}^{2+}$ ions remained almost constant in the $\mathrm{pH}$ range 2-4. However, there was a rapid increase in the removal percent from $\mathrm{pH} 4$ to alkaline region. This could be associated with the formation of $\mathrm{Cd}(\mathrm{OH})_{2}$ and $\mathrm{Cd}(\mathrm{OH})_{4}^{-}$ species which might be more attracted to the adsorbent

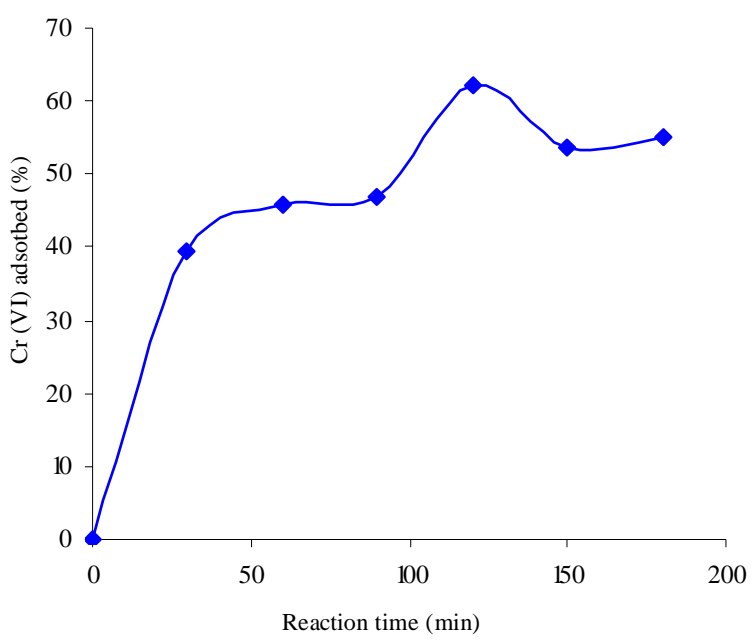

Fig. 7: Effect of contact time on Cr (VI) adsorption

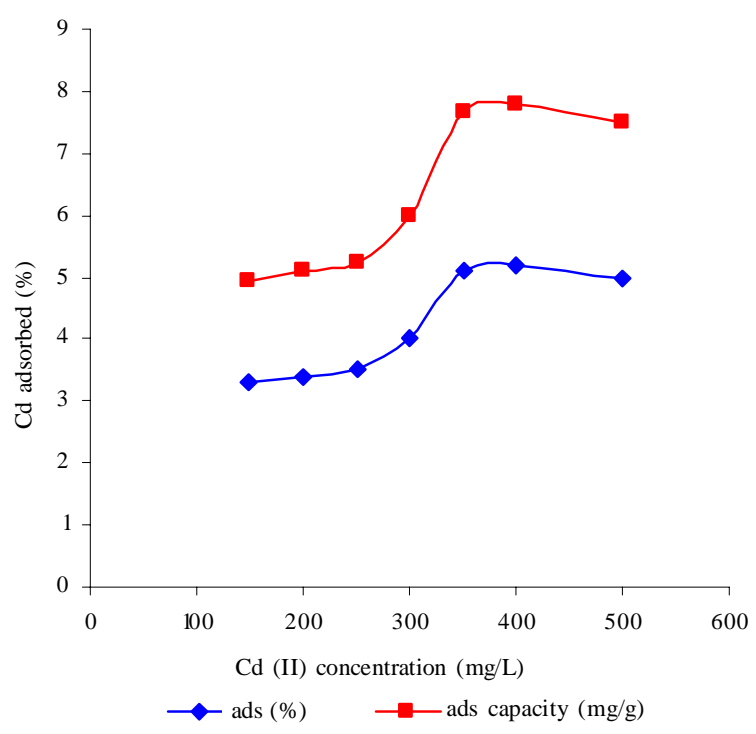

Fig. 8 Effect of $\mathrm{Cd}^{2+}$ ion concentrations on \% uptake 
rather than the positively charged $\mathrm{Cd}^{2+}$ ions. At lower $\mathrm{pH}$, the surface of the adsorbent became positively charged as the $\mathrm{OH}^{-}, \mathrm{NH}_{2}{ }^{-}$and other such groups become protonated. This will result in the increase in electrical repulsion between the adsorbent surface and the species to be adsorbed. At higher $\mathrm{pH}$, the surface of the adsorbent was almost neutral and thus resulting in minimal repulsion between the adsorbent and the adsorbate. Doyurum and Celik, 2006, carried out adsorption studies of Cd (II) They varied their $\mathrm{pH}$ from 3.5 to 6 and $30 \%$ uptake of Cd (II) from its solutions was obtained. Their results are significantly low compared to the uptake obtained in the present study. This could mean possibly that the adsorption properties of tassel were more influenced by $\mathrm{pH}$ than those of olive cake.

\section{Effect of adsorbent concentration on Cd (II) removal/ dosage}

The impact of adsorbent dose on the adsorption of Cd(II) in shown is Fig. 10. From Fig. 10, it can be observed that there is a general increase in the adsorption of Cd(II) as the adsorbent dose increased. The other parameters like in previous investigations were kept constant during the contact process. Solutions of 150 $\mathrm{mg} / \mathrm{L}$, were equilibrated at $25^{\circ} \mathrm{C}$ for $1 \mathrm{~h}$ at agitation speed of $100 \mathrm{rpm}$ at $\mathrm{pH}$ of 2 and a mass of $0.2 \mathrm{~g}$ tassel was used. Not much work has been reported on the effect of adsorbent dose on Cd (II) sorption.

\section{Effect of temperature on Cd (II) adsorption}

The impact of temperature on the adsorption of Cd (II) is shown in Fig. 11. From Fig. 11, it can be deduced that the adsorption capacity of tassel on Cd(II) decreased

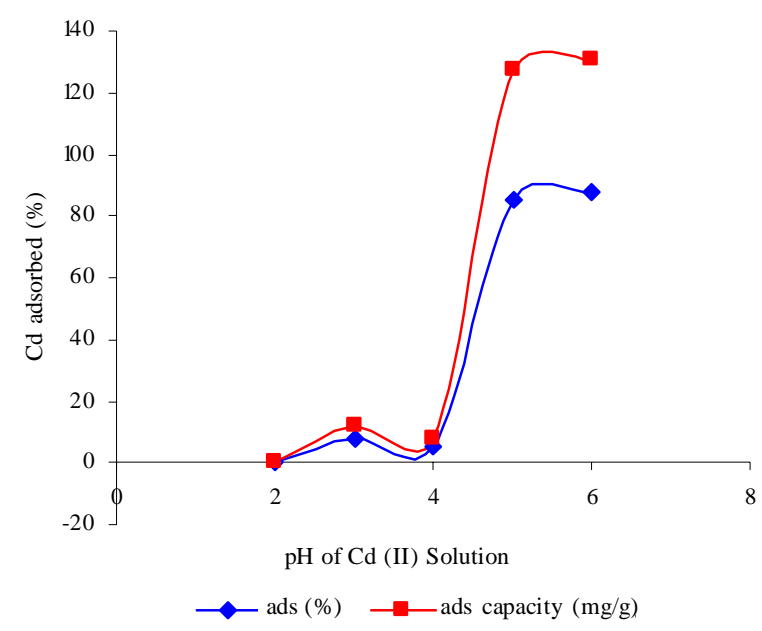

Fig. 9: Effect of $\mathrm{pH}$ on \% removal of $\mathrm{Cd}^{2+}$ ions with increase in temperature. Temperature can have a dual effect in adsorption mechanisms. Increase in temperature of the system will result in increase in the kinetics of the adsorbate species. This means particles will travel at a faster rate to the surface to get adsorbed. However, the adsorbed species might gain enough energy from temperature of the system and get desorbed at even a faster rate than adsorption rate. From this study, it was observed that the increase in temperature resulted in decrease in removal percentage in the temperature range 25 to $65{ }^{\circ} \mathrm{C}$ (Fig. 11). However, thereafter, an increase is observed. The increase in adsorption after $65{ }^{\circ} \mathrm{C}$ could be inferred to the increase in functional groups at the surface of the adsorbent as more hydrolysis of the surface took place.

\section{The effect of contact time on Cd (II) adsorption}

The impact of contact time on adsorption of $\mathrm{Cd}$ (II) is shown in Fig. 3-12. A general increase in Cd (II) adsorption with contact time is observed in the initial stages and it then levelled off after about 200 min. The contact time is essential for the establishment of equilibrium during the adsortiondesorption process. From the results of this study, the maximum removal percentage of $54.9 \%$ occurred after $150 \mathrm{~min}$. There was a general increase in removal percentage from 15.7 to $54.9 \%$ as the contact time increased from 30 to $210 \mathrm{~min}$. After $210 \mathrm{~min}$, the removal percentage decreased a bit to about $53 \%$ and remain stable thereafter. Results reported by Doyurum and Celik (2006) showed that equilibrium was established after $40 \mathrm{~min}$. In their study, more than $80 \%$ uptake of Cd (II) was achieved.

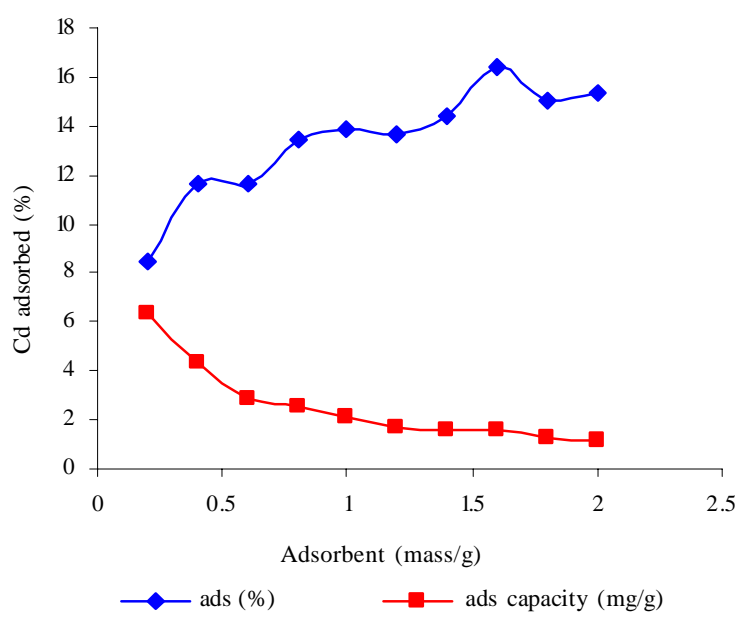

Fig. 10: Effect of adsorbent dose on \% removal of $\mathrm{Cd}^{2+}$ ions 


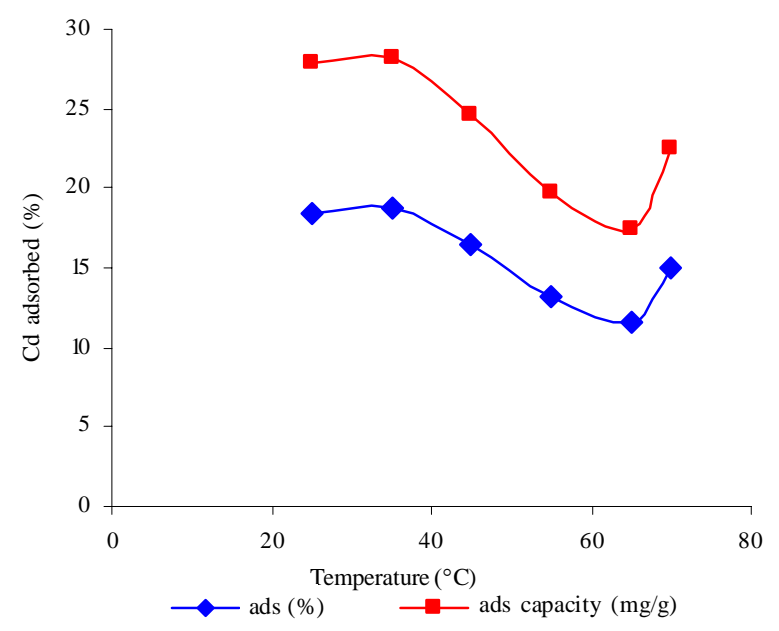

Fig. 11: Effect of temperature on $\mathrm{Cd}^{2+}$ ion adsorption

\section{CONCLUSION}

The aim of this work was to study the dependence of adsorption on adsorbent and adsorbate (chromium (VI) and cadmium (II)) characteristics by means of batch studies. The removal of $\mathrm{Cr}$ (VI) from aqueous solutions strongly depended on $\mathrm{pH}$ of the solution, adsorbent mass, initial Cr (VI) concentration, contact time and adsorbent mass. For $\mathrm{Cr}(\mathrm{VI})$, the maximum adsorption was obtained at $\mathrm{pH} 2.0$. A temperature of $45^{\circ} \mathrm{C}$ gave a maxima in the temperature variation studies for Cr (VI). Maximum removal of $\mathrm{Cr}$ (VI) from aqueous solutions can be obtained if all of the five process parameters are optimised. The removal of Cd (II) from its aqueous solutions was also parameter dependent. However, this metal exhibited poor extraction percentage compared to $\mathrm{Cr}$ (VI). The adsorption of Cd (II) was most influenced by the $\mathrm{pH}$ of the solution. A removal of $87.4 \%$ was observed at pH 5 at $25^{\circ} \mathrm{C}$. The adsorbent mass and initial Cd (II) concentration had minimal influence on the removal of Cd (II) from its aqueous solutions. From this study, it was observed that tassel can be used as an alternative low cost adsorbent for $\mathrm{Cr}$ (VI) and Cd (II) remediation for polluted water and wastewater. If tassel is to be used as a low cost adsorbent, there is a need to adjust the $\mathrm{pH}$ of the solution to optimal values obtained in this study. It is further recommended that chemical modification of the adsorbent be done to further improve the adsorption efficiency of the material.

\section{REFERENCES}

Abdel-Ghani, N. T.; Hefny, M.; El-Chagbaby, G. A. F.; (2007). Removal of lead from aqueous solution using low cost abundantly available adsorbents. Int. J. Environ. Sci. Tech., 4 (1), 67-73 (7 pages).

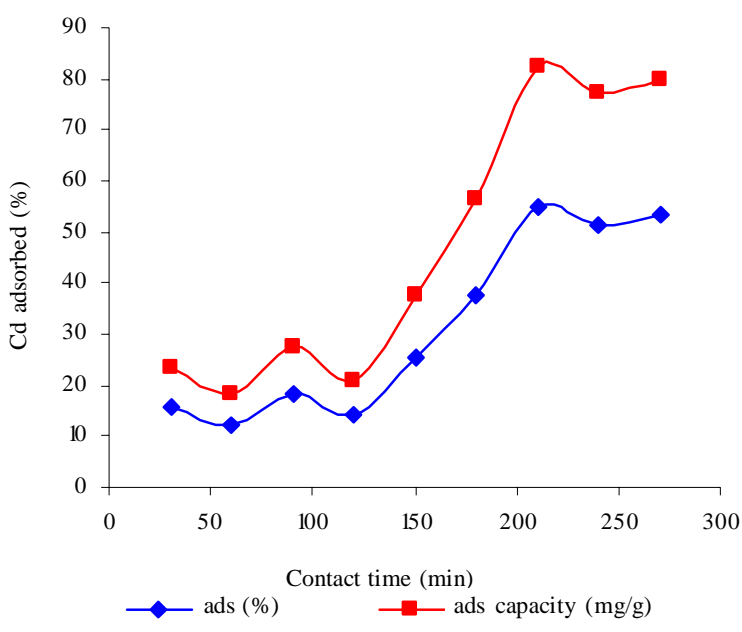

Fig. 12: Effect of contact time on \% uptake of Cd(II)

Abia, A. A.; Igwe, J. C., (2005). Sorption kinetics and intraparticulate diffusivities of $\mathrm{Cd}, \mathrm{Pb}$ and $\mathrm{Zn}$ ions on maize cob. Afr. J. Biotech., 4 (6), 509-512 (4 pages).

Álvarez-Ayuso, E.; García-Sánchez, A., (2007). Removal of cadmium from aqueous solutions by palygorskite. J. Hazard. Mater., 147 (1-2), 594-600 (7 pages).

Amuda, O. S.; Giwa, A. A.; Bello, I. A., (2007). Removal of heavy metal from industrial wastewater using modified activated coconut shell carbon. Biochem. Eng. J., 36 (2), 174-181 (8 pages).

Babel, S.; Kurniawan, T. A., (2004). Cr (VI) removal from synthetic wastewater using coconut shell charcoal and commercial activated carbon modified with oxidizing agents and/or chitosan. Chemosphere, 54 (7), 951-967 (17 pages).

Bailey, S. E.; Olin, T. J.; Bricka, R. M.; Adrian, D., (1999). A review of potentially low-cost sorbents for heavy metals. Wat. Res., 33 (11), 2469-2479 (11 pages).

Cardenas, G.; Mirand, S. P., (2004). FTIR and TGA studies of chitosan composite films. J. Chil. Chem. Soc., 49 (4), 291295 (5 pages).

Chauhan, G. S.; Jaswal, S.; Verma, M., (2006). Post fnctionalisation of carboxtmethylated starch and acrylonitrile based networks through amidoximation for use as ion sorbents. Carbohydra. Poly., 66 (4), 435-443 (9 pages).

Cohen, R. R. H., (2006). Use of microbes for cost reduction of metal removal from metal and mining industry waste streams. J. Cleaner Produc., 14 (12-13), 1146-1157 (12 pages).

Dakiky, M.; Khamis, M.; Manassra, A.; Mer'eb, M., (2002). The selective adsorption of chromium (VI) in industrial wastewater using low-cost abundantly available adsorbents. J. Adv. Environ. Res., 6 (4), 533-540 (8 pages).

Dang, V. B. H.; Doan, H. D.; Dang-Vu, T.; Lohi, A., (2009). Equilibrium and kinetics of biosorption of cadmium (II) and copper (II) ions by wheat straw. Bioresource Tech., 100 (1), 211-219 (9 pages).

Doyurum, S.; Celik, A., (2006). Pb (II) and Cd (II) removal from aqueous solutions by olive cake. J. Hazard. Mater., 138 (1), 22-28 (7 pages).

Dubey, S. P.; Krishna, G., (2007). Adsorption of chromium (VI) on low cost adsorbents derived from agricultural waste material. J. Hazard. Mater., 145 (3), 465-470 (6 pages). 
Gupta, V. K.; Mohan, D.; Sharma, S.; Park, K. T., (1999). Removal of chromium (VI) from electroplating industry wastewater using bagasse fly ash-a sugar industry waste material., The Environmentalist, 19 (2), 129-136 (8 pages).

Jusoh, A.; Shiung, L. S.; Ali, N.; Noor, M. J. M. M., (2007). A simulation study of the removal efficiency of granular activated carbon on cadmium and lead. Desalination, 206 (13), 9-16 (8 pages).

Karbassi, A. R.; Shankar, R. (1994). Magnetic susceptibility of bottom sediments and suspended particulates from MulkiPavanje River, estuary, and adjoining shelf, west coast of India. J. Geophysic. Res., 99 (5), 10207-10220 (14 pages).

Kumar, U., (2006). Agricultural products and by-products as a low cost adsorbent for heavy metal removal from water and wastewater: A review. Sci. Res. Essay, 1 (2), 33-37 (5 pages).

Kurniawan, T. A.; Chan, G. Y. S.; Lo, W. h.; Babel, S., (2006). Comparison of low-cost adsorbents for treating wastewater laden with heavy metals. Sci. Tot. Environ., 366 (2-3), 409426 (18 pages)

Lakatos, J.; Brown, S. D.; Snape, C. E., (2002). Coals as sorbents for the removal and reduction of hexavalent chromium from aqueous waste streams. Fuel, 81 (5), 691-698 (8 pages).

Malakootian, M.; Nouri, J.; Hossaini, H., (2009). Removal of heavy metals from paint industries wastewater using Leca as an available adsorbent. Int. J. Environ. Sci. Tech., 6 (2), 183190 (8 pages).

Malkoc, E.; Nuhoglu, Y.; Dundar, M., (2006). Adsorption of chromium (VI) on pomace-An olive industry waste: Batch and column studies. J. Hazard. Mater., 138 (1), 142-151 (10 pages).

Merroun, M. L.; Omar, N. B.; González-Muňoz, M. T.; Arias, J. M., (1998). Myxococcus xanthus biomas as adsorbent for lead. J. Appl. Microbiol., 84 (1), 63-67 (5 pages).

Mohan, D.; Pittman, C. A., (2006). Activated carbons and low cost adsorbents for remediation of tri-and hexavalent chromium from water. J. Hazard. Mater., 137 (2), 762-811 (50 pages).

Naiya, T. K.; Bhattacharya, A. K.; Das, S. K., (2009). Adsorption of $\mathrm{Cd}$ (II) and $\mathrm{Pb}$ (II) from aqueous solutions on activated alumina. J. Coll. Interf. Sci., 333 (1), 14-26 (13 pages).

Namasivayam, C.; Yamuna, R. T., (1995). Adsorption of chromium (VI) by a low cost adsorbent: Biogas residual slurry. Chemosphere, 30 (3), 561-578 (18 pages).

O’Connell, D. W.; Birkinshaw, C.; O’Dwyer, T. F., (2008). Heavy metal adsorbents prepared from the modification of cellulose: A review. Bioresour. Tech., 99 (15), 6709-6724 (16 pages).
Ramos, R. L.; Rangel-Mendez, J. R.; Coronado, R. M., (1997). Adsorption of cadmium (II) from aqueous solution onto activated carbon. Wat. Sci. Tech. 35 (7), 205-211 (7 pages).

Singh, C. K.; Sahu, J. N.; Mahalik, K. K.; Mohanty, C. R.; Mohan, B. R.; Meikap, B. C., (2007). Studies on the removal of $\mathrm{Pb}$ (II) from wastewater by activated carbon developed from Tamarind wood activated with sulphuric acid. J. Hazard. Mater., 153 (1-2), 221-228 (8 pages).

Srivastava, H. C. P.; Mathur, R. P.; Mehrotra, I., (1986). Removal of chromium from industrial effluents by adsorption on sawdust. Environ. Tech., 7 (1-12), 55-63 (9 pages).

Udy, M. J., (1956). Chromium. Reinhold publishing corporation, New York.

Vandecasteele, B.; Quataert, P.; Tack, F. M. G., (2007). Uptake of $\mathrm{Cd}, \mathrm{Zn}$ and $\mathrm{Mn}$ by willow increases during terrestrialisation of initially ponded polluted sediments. Sci. Tot. Environ., 380 (1-3), 133-143 (11 pages).

Wan Ngah, W. S.; Hanafiah, M. A. K. M., (2008). Removal of heavy metal ions from wastewater by chemically modified plant wastes as adsorbents: A review. Bioresource Tech., 99 (10), 3935-3948 (14 pages).

Wang, J.; Zhang, D.; Lawson, T. R.; Bartsch, R. A., (2009). Sorption of heavy metal ions by silica gel-immobilised, proton-ionisable calyx[4]arenes. Talanta, 78 (2), 477-483 (7 pages).

Zhu, C.; Luan, Z.; Wang, Y.; Shan, X., (2007). Removal of cadmium from aqueous solutions by adsorption on granular red mud (GRM). Sepr. Purif. Tech., 57 (1), 161-169 (9 pages).

Zvinowanda, C. M.; Okonkwo; J. O.; Agyei, N. M.; Forbes, P.; Mpangela, V.; Phaleng, J.; Shabalala, P. N.; Dennis, T.; Ozoemena, K. I., (2008a). Biosorption of toxic metals: The potential of maize tassel for the removal of $\mathrm{Pb}$ (II) from aqueous solutions. Fresen. Environ. Bull., 17 (7), 814-818 (5 pages).

Zvinowanda, C. M.; Okonkwo, J. O.; Agyei, N. M.; Shabalala, P. N., (2009a). Physicochemical characterisation of maize tassel adsorbent: Part I. Surface texture, microstructure and thermal stability. J. Appl. Poly. Sci., 111 (4), 1923-1930 (8 pages).

Zvinowanda, C. M.; Okonkwo, J. O.; Agyei, N. M.; Sekhula, M. M.; Sadiku, R., (2009b). Application of maize tassel for the removal of $\mathrm{Pb}, \mathrm{Se}, \mathrm{Sr}, \mathrm{U}$ and $\mathrm{V}$ from borehole water contaminated with mine wastewater in the presence of alkaline metals. J. Hazard. Mater., 164 (2-3), 884-891(8 pages).

Zvinowanda, C. M.; Okonkwo, J. O.; Agyei, N. M.; Shabalala, P. N., (2008b). Preparation and characterisation of biosorbents made from tassel. Canadian J. Pur. Appl. Sci. 2 (3), 476-480 (5 pages).

AUTHOR (S) BIOSKETCHES
Zvinowanda, C. M., Ph.D. research candidate in wastewater processing niche area, Department of Environmental, Water and Earth Sciences,
Tshwane University of Technology, South Africa. Email: zvinowandacm@tut.ac.za
Okonkwo, J. O., Ph.D., Research and innovation professor, Department of Environmental, Water \& Earth Sciences, Tshwane University of
Technology, South Africa. Email: okonkwooj@tut.ac.za
Shabalala, P. N., B.Tech., Environmental researcher, AER (Environmental Business Services Section), SGS Group, Johannesburg, South
Africa. Email: pride@ecoserv.com
Agyei, N. M., Ph.D., Senior lecturer, Department of Chemistry, University of Limpopo, Medunsa, South Africa.
Email:agyei@ul.ac.za

This article should be referenced as follows:

Zvinowanda, C. M.; Okonkwo, J. O.; Shabalala, P. N.; Agyei, N. M., (2009). A novel adsorbent for heavy metal remediation in aqueous environments. Int. J. Environ. Sci. Tech., 6 (3), 425-434. 